\title{
THE SIGNIFICANCE OF LINGUISTICS IN THE STUDY OF PHILOSOPHY
}

\author{
Istikomah \\ Sekolah Tinggi Filsafat Islam (STFI) Sadra \\ Nurhayati $^{*}$ \\ Universitas Indraprasta PGRI \\ *) Correspondences author: Jln. Nangka No.58 C Tanjung Barat, Jagakarsa, Jakarta Selatan, Indonesia; \\ e-mail: nurhayatihasbi1@gmail.com
}

\begin{abstract}
Since the era of Greece and Rome in the 4-2 century BC, until this Postmodern one, language has been one of the most central and core issues of philosophical studies. Language and Philosophy both focus on issues related to structure and meaning in natural language, as discussed in the philosophy of language and other disciplines, among others; philosophical theories about meaning and truth, presuppositions, implicatures, speech acts, etc. This article discusses several case studies that illustrate the relationship between the philosophy of language through three branches of linguistics; syntax (Stanley, 2000), semantics (von Fintel, 2001), and pragmatics (Potts, 2005). The results of the study reveal a significance and interdependence between philosophy and language. Philosophy requires language as a means of communicating ideas and also as an object of study in philosophy. Meanwhile, language also badly needs philosophy as a means or method to analyze systematically to get solutions to solving linguistic problems.
\end{abstract}

Keywords: Linguistics, philosophy, syntax, semantics, and pragmatics.

Article History: Received: 25/05/2021; Revised: 11/06/2021; Accepted: 11/06/2021; Published: 30/06/2021.

How to Cite (MLA $7^{\text {th }}$ ): Istikomah and Nurhayati. "The Significance of Linguistics in the Study of Philosophy." Hortatori: Jurnal Pendidikan Bahasa dan Sastra Indonesia 5.1 (2021): 51-60. Print/Online. Copyrights Holder: Istikomah, Nurhayati. First Publication: Hortatori: Jurnal Pendidikan Bahasa dan Sastra Indonesia (2017).

\section{Pendahuluan}

Minat seseorang terhadap kajian bahasa bukanlah hal yang baru sepanjang sejarah filsafat. Semenjak munculnya Retorika Corax dan Cicero pada zaman Yunani dan Romawi abad 4 - 2 SM hingga saat ini (Post Modern), bahasa merupakan salah satu tema kajian filsafat yang sangat menarik. Sesorang akan mampu berfilsafat jika bahasa itu ada, begitu juga dengan adanya bahasa, seseorang itu akan berbahasa sesuai dengan hasil penalaran, proses kerja otak dan menghasilkan pengetahuan yang diolah melalui filsafat. Jadi, bahasa dan filsafat bagaikan dua sisi mata uang yang senantiasa bersatu dan tak terpisahkan.

Hadirnya istilah filsafat bahasa dalam ruang dunia filsafat dapat dikatakan sebagai suatu hal yang baru. Istilah ini muncul bersamaan dengan kecenderungan filsafat abad ke-20 yang bersifat logosentris. Oleh karena itu, sangat wajar apabila ditemukan kesulitan untuk mendapatkan pengertian yang pasti mengenai apa sebetulnya yang dimaksud dengan filsafat bahasa.

Pada zaman Yunani kuno, bahasa sedikit banyak menjadi salah satu objek kajian oleh para filsuf. Kaelan (1998) menjelaskan bahwa pada masa itu beberapa filsuf mengembangkan pemikiran dan mengemukakan gagasan mereka tentang bahasa. Sebut saja misalnya Herakleitos yang memberikan gagasannya tentang 'kata' (logos). Ia berpendapat bahwa logos bukan merupakan gejala antropologis belaka namun mengandung kebenaran kosmis yang universal. Plato bahkan lebih luas menggambarkan pemikirannya tentang bahasa. Ia meyakini bahwa bahasa adalah ekspresi pikiran yang dimediasi oleh apa yang ia sebut dengan 'onoma' dan 'rhemata'. 'Onomata' (jamaknya 'onoma') adalah subjek dalam kaitan 
dengan subjek logis, sementara 'rhemata' (jamaknya 'rhema') merupakan verba dalam tata bahasa dan predikat dalam hubungannya dengan makna logis. Ini menunjukkan bahwa benih-benih filsafat bahasa telah mulai dikembangkan pada masa kejayaan Yunani itu (85).

Filsafat bahasa selalu dipahami pada dua perspektif berbeda, yaitu, pertama, filsafat yang menggunakan bahasa sebagai alat analisis konsep-konsep, dan kedua, filsafat yang mengkaji tentang bahasa sebagai materia yang dianalisis. Kedua pengertian ini berkembang sedemikian rupa menurut sudut pandang filsuf yang berbeda. Secara sederhana, Muntasyir (1988) memberikan definisi filsafat bahasa yaitu 'suatu penyelidikan secara mendalam terhadap bahasa yang dipergunakan dalam filsafat, sehingga dapat dibedakan pernyataan filsafat yang mengandung makna (meaningful) dengan yang tidak bermakna (meaningless) (51). Definisi ini menunjukkan bahwa bahasa menjadi materia yang dikaji untuk menghasilkan makna dari pernyataan-pernyataan filsafati.

Interaksi linguistik dan filosofi bahasa secara teratur mengilhami deskripsi yang bervarian. Seorang filsuf bahkan mendeskripsikannya sebagai "initial central sun, seminal and tumultuous: from time to time it throws off some portion of itself to take station as a planet," dan ia melanjutkan dengan menyarankan bahwa linguistik mungkin termasuk di antara satelit (Austin 71). Sedangkan dalam ungkapan seorang ahli bahasa, menyebutkan bahwa filsafat diibaratkan seperti "a rummage sale that sometimes offers useful items for the home improver" (Nunberg 671-680). Higginbotham menawarkan perspektif yang sangat ambigu bahwa "linguistics and philosophy, like steak and barbecue sauce, have much to give each other"(57). Dan interaksi kontemporer antara ahli bahasa dan filsuf bahasa memang begitu luas dan mendalam namun pada varian perspektif diatas ini gagal menangkap sejauh mana substansi makna relasional kedua bidang disiplin ilmu tersebut.

Mengikuti pepatah bahwa "better to show than tell" terhadap sesuatu tentang peran linguistik dalam filsafat bahasa, penulis akan fokus pada beberapa studi kasus yang menggambarkan aspek kunci dari hubungan ini. Entri ini harus dibatasi cakupannya. Partee (2005) memberikan penjelasan yang sangat baik tentang interaksi awal antara ahli bahasa dan filsuf, jadi entri ini berfokus pada sastra kontemporer daripada peran historis linguistik dalam filsafat bahasa (259-281). Selain itu, penulis mengesampingkan pengaruh luas linguistik pada subbidang filsafat lainnya, sebagaimana yang nyatakan Stanley \& Williamson (2001) seperti pengaruh psikolinguistik dalam filsafat pemikiran, semantik konstruksi pengetahuan dalam menilai intelektualisme dalam epistemologi, dan semantik penghitungan terkait peristiwa dalam metafisika ketekunan yang dinyatakan oleh Moss (411-444).

Berangkat dari fenomena hubungan antara dunia filsafat dan kebahasaan itulah, maka kajian ini akan mencoba menguraikan kaitan antara bahasa dan filsafat, terutama dalam konteks kaitannya yang lebih spesifik lagi, yakni hubungan antara filsafat bahasa dan tiga cabang linguistik — sintaksis, semantik, dan pragmatik.

Kajian ini akan diawali dengan uraian tentang pengertian atau pun hakikat mengenai sintaksis, semantik, dan pragmatik dari filsafat dan juga bahasa, serta yang tidak kalah pentingnya adalah pembahasan tentang pengertian filsafat linguistik itu sendiri. Kajian singkat ini akan diakhiri dengan kesimpulan tentang apa yang sudah dibahas pada uraian-uraian sebelumnya.

\section{Metode}

Mengkaji wacana bahasa, sebenarnya merupakan kajian tentang salah satu wujud substansi penting atas fenomena kebudayaan manusia, yakni berkaitan dengan sistem komunikasi yang dimilikinya. Hanya dengan proses komunikasi yang intensif dan efektif sebuah kebudayaan manusia dapat dibangun dan dipertahankan keberadaannya, Dalam kata-kata Umberto Eco (222) "Culture is significalion and communication and that humanity and society exist only when communicatioe and significative relationships are established" (22). Pendekatan kualitatif dalam artikel ini direalisasikan dengan mengaplikasikan kajian pustaka kritis di berbagai literatur yang relevan. Kemudian dilakukan literature review untuk mengumpulkan data peranan dan hubungan signifikan antara filsafat dan bahasa sekaligus kajian teori terkait konstruksi relasional antara bahasa dan filsafat dari perspektif diskursus filsafat linguistik. Data yang digunakan bersifat kualitatif. Data kualitatif adalah data yang biasanya dalam bentuk kata bukan angka.

Metode yang digunakan dalam studi ini bersifat kualitatif, dengan mendekati, mengetahui dan menginterpretasi hakikat mengenai sintaksis, semantik, dan pragmatik dari filsafat dan juga bahasa dengan pendekatan studi kasus. 


\section{Hasil dan Diskusi}

Filsafat bahasa merupakan cabang filsafat khusus yang memiliki objek material bahasa. Berbeda dengan cabang-cabang serta bidang-bidang filsafat lainnya, filsafat bahasa dalam perkembangannya tidak mempunyai prinsip-prinsip yang jelas dan terdefinisikan dengan baik (Alston, 1964 : 1). Hal ini disebabkan karena para penganut filsafat bahasa atau tokoh-tokoh filsafat bahasa masing-masing mempunyai perhatian dan caranya sendiri-sendiri, meskipun juga terdapat persamaan di antara mereka, yaitu bahwa mereka kesemuanya menaruh perhatian terhadap bahasa sebagai objek materi dalam berfilsafat.

Dalam membangun sebuah sistem komunikasi yang efektif, manusia memerlukan media/sarana simbolik, yakni berupa bahasa. Ini disebabkan, secara prinsip keberadaan kebudayaan yang dimiliki oleh manusia itu sendiri, juga terdiri atas gagasan-gagasan, nilai-nilai, dan hasil karya yang diwujudkan dalam bentuk simbol-simbol. A.L. Krocber dan C. Kluckhon dalam Culture, A Critical Review of Concepts and Definition (dalam The Liang Gie, 1977:127) dalam kaitannya dengan salah satu substansi makna kebudayaan yang senantiasa terkait erat dengan simbol/bahasa mengemukakan sebagai berikut. "Culture consists of patterns, explicit and implicit, of and for behavior ncguired and transmitted by symbol, constituting the distinctive achievemenis of human groups, including their embodiments in arlifacts...."

Senafas dengan hal dimaksud, Foley (2001:16) juga menegaskan peran simbol/ bahasa dalam hubungannya dengan budaya manusia, dengan mengadaptasi konsep antropologinya Geertz sebagai berikut. "Understanding and practices are realized for humans through symbols. One view af culture, then, is really as a system of symbols by which a human being enacts his/her embodied understanding. This is the view propounded by the influential school of symbolic anthropologu the best knowa representative of this view probably being Geertz, He vicws culture as a system of public meanings encoded in symbols and articulaled in behaviour seen as symbolic action...".

Sejalan dengan pandangan dimaksud, Wieman dan Walter dalam Toward an Analysis of Etlucs for Rhetoric (1957), mengungkapkan bahwa kemampuan menggunakan simbol ini merupakan salah satu sifat dasar manusia. Kemampuan ini sebagian orang mungkin menyebutnya keharusan, untuk mengubah data mentah hasil pengalaman indera menjadi simbol-simbol (bahasa), kita juga dapat menggunakan bahasa untuk menunjuk pada pengertian lain (seperti konsepsi, tujuan, nilai, cinta) dan untuk mewariskan pengetahuan dan wawasan dari generasi ke generasi. Singkatnya, daya simbolisasi bahasa ini, menurut Wieman dan Walter bertanggungjawab dan bahkan menjadi garansi atas kelangsungan hidup umat manusia (Johannesen, 1996).

Dillistone yang mengadaptasi pandangan sosiolog R. Mac Iver dalam Society (1950) (dalam Dillistone, 2002) juga menegaskan bahwa simbol/bahasa telah dan masih tetap memiliki arti yang sangat penting dalam kehidupan manusia, sebagaimana tampak dalam kutipan berikut. "Kesatuan sebuah kelompok, seperti semua nilai budayanya, pasti diungkapkan melalui simbol.... Simbol sekaligus merupakan sebuah pusat perhatian yang tertentu, sebuah sarana kamunikasi, dan landasan pemahaman bersama..., Setiap komunikasi, dengan bahasa atau sarana lain, menggunakan simbol-simbol/ bahasa. Masyarakat hampir tak mungkin ada tanpa simbol-simbol."

Oleh karena begitu eratnya fenomena kebudayaan manusia dengan sistem simbol, bahkan akhirnya Ernest Cassier dalam buku An Essay on Man, An Introduction to a Philosophy of Human Culture, menyebut makhluk manusia itu sebagai "animal symbolicum' (Herusatoto, 2001) Cassier menegaskan, bahwa manusia itu tidak pernah melihat, menemukan, dan mengenal dunianya secara langsung, kecuali melalui berbagai simbol/ bahasa. Paralel dengan pandangan tersebut, juga dikemukakan oleh Mudji Sutrisno (1999), yakni bahwa kebudayaan manusia itu difahami sebagai jagad (istilah Jawa: dunia) makna dan nilai yang dikomunikasikan melalui lambang-lambang atau simbol-simbol, yang menempatkan manusiamanusia pelakunya sebagai makhluk 'symbolizing, conceptualizing and meaning seeking animal (makhluk perajut, perumus, pencari makna yang diungkapkan lewat simbol/ bahasa).

Keberadaan sistem simbolik kebudayaan manusia itu, meng-'ada" dalam bentuk sistem bahasa dalam arti yang luas, yang digunakan sebagai media komunikasi. Sebagimana diketahui, bahwa variabel komunikasi merupakan dasar yang menentukan keberadaan dan struktur suatu masyarakat (Susanto, 1976). Dengan komunikasi menggunakan sistem dan simbol bahasa, akhirnya manusia saling pengaruh mempengaruhi, sehingga terbentuklah pengalaman kolektif yang sama dalam satu masyarakat. Dalam pandangan Frederick B, Parker dan Wilfred A. Anderson melalui buku Society, Ifs Organization and Operation (1964) (dalam Susanto, 1976), bahwa dengan mekanisme komunikasi, manusia memberitahukan 
dan menyebarkan apa yang dirasakan dan apa yang diinginkannya. Bahkan Anderson dan Parker menegaskan, bahwa komunikasi adalah dasar bagi "human relations and culture". Melalui komunikasi pula, menurut J. Vialatoux dalam Signification Humaine du Travail (1966), akan terbentuklah masyarakat yang paling sederhana, yakni masyarakat yang oleh Ferdinand Toennies disebut 'cemeinschaft', dan oleh Emile Durkheim disebut sebagai "solidaritas mekanis' atau bentuk kohesi sosial yang primitif, Kemudian melalui komunikasi yang semakin efektif, selanjutnya berkembang dan terbentuklah masyarakat yang menurut Ferdinand Toennies disebut 'geselIschaft', atau dalam istilahnya Emile Durkheim dikenal dengan "masyarakat organis'. Dalam konteks makna masyarakat 'gesellschaff' inilah, akhirnya komunikasi memegang peranan yang semakin vital dan strategis bagi manusia dan peradabannya (Susanto, 1976).

Dalam konteks kajian ini penulis hanya akan memfokuskan pada hubungan antara filsafat bahasa dan tiga cabang linguistik - sintaksis, semantik, dan pragmatik. Dimana pada setiap bagian, penulis akan membahas melalui studi kasus dan kemudian secara singkat menyebutkan contoh penting lainnya, khususnya tentang peran linguistik dalam filsafat bahasa.

Dalam tulisannya tentang Linguistik dan Filsafat (2000), Jason Stanley berpendapat bahwa tidak ada 'konstituen yang tidak diartikulasikan' (unarticulated constituents). Menurutnya semua efek konteks kebenaran-kondisional dapat dilacak ke bentuk logis. Studi kasus pertama yang dibahas merujuk pada Stanley (2000) : perdebatan tentang apakah sebenarnya ada konstituen yang tidak terartikulasikan dari proposisi yang diungkapkan oleh sebuah ucapan (utterances). Misalnya, ada 2 phrase yang dianggap tidak bertentangan dimana ungkapan kalimat (1) dan (2) dibawah ini sebagai context-sensitive, dan tempat di mana keduanya diucapkan relevan dengan kondisi kebenarannya:

\section{(1) Para pelayan menyajikan makanan di restoran dekat sini. \\ (2) Para pelayan menyajikan makanan di rumah makan lokal.}

Berbeda dengan apa yang diklaim oleh para pendukung pragmatics $(T C P)$, beberapa orang berpendapat bahwa ungkapan diatas tidak mengandung elemen apa pun yang menunjuk tempat konteks ucapan (utterances). Sebaliknya ada "pasca-semantik" tingkat interpretasi di mana konstituen yang tidak diartikulasikan dari proposisi tersebut diidentifikasi. Perry (1986) memperkenalkan gagasan tentang konstituen yang tidak diartikulasikan (unarticulated constituents), dan Perry (1998) menjelaskan: "Dalam beberapa kasus referensi implisit terdapat fitur, jejak, semacam ekspresi bayangan, yang berfungsi sebagai pengganti ekspresi, sehingga konstituen yang dirujuk benar-benar tidak diartikulasikan. . . Saya tertarik pada kemungkinan teoretis dan koherensi dari konstituen yang benar-benar tidak diartikulasikan".

Menurut pandangan luas, konteks berperan dalam interpretasi truth-conditional hanya untuk membantu menentukan denotasi indeksikal dan ekspresi context-sensitive lainnya. Ekspresi seperti itu merupakan variabel bebas yang nilai semantiknya harus ditetapkan secara kontekstual. Dalam beberapa kasus, penetapan kontekstual bersifat otomatis dan teratur (rule-governed). Jadi, rujukan 'Saya' ditentukan secara otomatis atas dasar aturan linguistik, tanpa mempertimbangkan keyakinan dan niat pembicara. Dalam kasus lain, denotasi ekspresi sensitif konteks (context-sensitive) ditentukan secara pragmatis. Misalnya, frasa posesif seperti 'Buku Amir' bisa dibilang memiliki arti seperti Buku yang memiliki hubungan R dengan Amir. Variabel bebas 'R' harus diberi nilai tertentu secara kontekstual; tetapi nilai itu tidak ditentukan oleh suatu aturan. Apa yang dimaksud dengan kemunculan frasa 'Buku Amir' pada akhirnya bergantung pada apa yang dimaksud oleh pembicara yang mengucapkannya. Ketergantungan pada makna pembicara adalah ciri khas ekspresi 'yang secara semantik kurang ditentukan', yang meresap dalam bahasa alami.

Sebenarnya ada berbagai contoh penting lainnya dari argumen sintaksis yang berkaitan dengan pertanyaan klasik dalam filsafat bahasa. Beberapa argumen mengenai ruang lingkup pembilang telah diterapkan dalam menilai analisis kuantitatif dari deskripsi tertentu untuk diskusi kritis dari beberapa literatur ini (Glanzberg, 2007). Dalam hal ini, pihak lain telah menerapkan argumen sintaksis dalam menilai akun kuantitatif dari demonstrasi yang kompleks; (King, 2001) untuk satu contoh dan Lepore \& Johnson (2002) dan King (2010) untuk diskusi kritis. Dan telah disarankan bahwa representasi sintaksis yang tepat dari tense memiliki implikasi pada sifat objek pernyataan, misal, untuk apakah objek tersebut memiliki nilai kebenaran yang bervariasi dari waktu ke waktu (Ninan, 2010), yakni untuk diskusi kritis tentang peran yang dimainkan argumen sintaksis dalam literatur ini.

Studi kasus kedua tentang pengaruh linguistik dalam filsafat bahasa disajikan dalam diskusi tentang subjungtif kondisional (Subjunctive Conditionals) dalam von Fintel (2001). Analisis tentang subjungtif 
telah menjadi minat filosofis sejak Chisholm (1946) dan Goodman (1947). Stalnaker (1968) dan pendukung Lewis (1973) sebagai teori pembanding tentang subjungtiva, dan banyak pakar lainnya mengamati secara cermat perselisihan mereka tersebut. Tetapi kisah-kisah problematik dan polemik yang diberikan oleh para filsuf ini memang memiliki fitur utama: menurut kedua pihak bahwa penguatan Anteseden itu tidak valid. Misalnya, mempertimbangkan urutan yang tepat dari Lewis (1973) berikut ini : (I)

\section{Pernyataan (a): \\ Jika AS melemparkan senjatanya ke laut besok, akan ada perang. \\ Pernyataan (b): \\ Jika AS dan kekuatan nuklir lainnya semua melemparkan senjata mereka ke laut besok, akan ada perdamaian.}

Stalnaker dan Lewis sama-sama menganjurkan analisis kondisional yang sangat ketat, yang menurutnya 'jika $p$, akan $q$ ' mengungkapkan proposisi yang benar secara gamblang seandainya semua dunia "p" terdekat adalah dunia " $q$ ". Secara khusus, Lewis (1973) mengatakan bahwa 'if $p$, would q' mengungkapkan proposisi yang tidak nampak benar di dunia seandainya beberapa dunia " $p$ and $q$ " lebih dekat ke dunia itu daripada dunia "p-and-not-q". Sedangkan Stalnaker (1968) mengatakan bahwa 'jika p, akan q' mengungkapkan proposisi yang benar di dunia sendainya dunia "p" terdekat adalah dunia "q". Keduanya memprediksi bahwa hal ini memperkuat anteseden (Pernyataan-a) tidak perlu mempertahankan kebenarannya, jadi (Pernyataan-a) dan (Pernyataan-b) keduanya bisa benar.

Diskursus berikutnya dalam semantik formal menantang analisis kondisional yang sangat ketat. Dalam hal ini von Fintel (1999 \& 2001), berpendapat bahwa Stalnaker dan Lewis gagal menjelaskan ketidaksempurnaan urutan lain seperti: (II)

\section{Pernyataan (a): \\ Jika AS dan kekuatan nuklir lainnya semua melemparkan senjata mereka ke laut besok, akan ada perdamaian. \\ Pernyataan (b): \\ Jika AS melemparkan senjatanya ke laut besok, akan ada perang}

Untuk menjelaskan asimetri antara (I) dan (II), von Fintel mendukung analisis bersyarat yang ketat (Gillies, 2007). Dia berpendapat bahwa 'jika p, akan q' benar jika "semua dunia p" dalam domain yang ditentukan secara kontekstual adalah "dunia q", dan dia menambahkan bahwa 'jika $p$, akan q' itu sendiri menuntut domain yang relevan berisi beberapa "dunia p". Jadi setelah pembicara mengucapkan (II-a), konteksnya bergeser sehingga domain dari persyaratan ketat yang diungkapkan dalam (II-b) berisi dunia di mana semua kekuatan nuklir dilucuti, dan (II-b) oleh karena itu gagal menjadi kenyataan. Singkatnya, von Fintel berargumen bahwa dia dapat mengalahkan Stalnaker dan Lewis di permainan mereka sendiri, karena analisis ketat yang berbeda-beda yang dilakukan dengan sangat baik pada akuntansi untuk (I) gagal untuk menjelaskan penilaian kami tentang (II) (Moss, 2009 dan Moss, 2010 untuk tanggapan atas nama analisis bersyarat yang selalu ketat).

Lebih jauh, von Fintel tidak hanya tertarik pada akuntansi penilaian tentang urutan yang lebih kreatif dari subjungtiva. Dia juga mengemukakan keprihatinan semantik khas yang berkaitan dengan perselisihan. Motivasi linguistik yang paling menarik untuk analisis kondisional ketatnya berasal dari fakta tentang item polaritas negatif (Negative Polarity Items-NPI), ekspresi yang dilisensikan hanya dalam lingkup negasi dan ekspresi "negatif" lainnya. Apa pun pendapat orang tentang debat ini, jelas bahwa fakta tentang item polaritas negatif menyajikan data lebih lanjut bagi filsuf mana pun yang mengembangkan teori kondisional subjungtif.

Selain tes yang melibatkan item polaritas negatif, beberapa alat dari semantik secara teratur muncul dalam filosofi sastra bahasa. Filsuf menggunakan pasangan kalimat minimal dalam menyusun dan menguji hipotesis. Diskusi ellipsis frase kata kerja dan kendala mengikat tersebar di seluruh literatur. Studi lintaslinguistik telah memperkenalkan batasan pada teori filosofis dari fragmen bahasa (misalnya hubungan antara penelitian tentang bukti dan modal epistemik, dan diskusi demonstratif non-Inggris yang diuraikan dalam Wolter, 2009). Tes untuk membedakan prediksi dari kalimat kopular spesifik telah memainkan peran dalam perdebatan tentang rujukan dari 'that'-clauses (Pryor, 2007). Contoh-contoh ini menunjukkan bahwa 
mungkin semantik juga merupakan sumber item yang berguna untuk mereformulasi disiplin studi dalam bidang ini.

Selain menyediakan alat yang berguna bagi filsuf, semantik adalah objek minat penelitian yang umum bagi ahli bahasa dan filsuf bahasa. Semantikis telah mempelajari secara harfiah setiap topik bahasannya. Jelas ada banyak penelitian bersama tentang semantik dari berbagai ekspresi rujukan, termasuk ekspresi anaphoric (Anaphora), deskripsi tak terbatas dan pasti (Descriptions), dan demonstratif kompleks (Indexicals and Demonstratives). Analisis semantik dari fragmen bahasa lain memiliki implikasi untuk pertanyaan mendasar tentang sifat pernyataan, misalnya penelitian tentang modal epistemik (Swanson 2008) dan bahasa lain dari ketidakpastian subjektif dan predikat selera pribadi sebagaimana dalam teori Relativisme. Para filsuf juga secara aktif terlibat dalam penelitian linguistik pada tahap pengembangan kerangka kerja semantik baru, misalnya dari pengembangan sistem semantik formal (Lewis 1970, Montague 1970, 1973) hingga event semantics (Davidson 1967), pengindeksan ganda (Kamp 1971, Kaplan 1977), semantik alternatif (Hamblin 1973), semantik dinamis (Stalnaker 1974, 1978, Lewis 1975, 1979a, 1979b, Kamp 1981, Veltman 1996), semantik situasi (Barwise \& Cooper 1981), dan proposisi terstruktur (Cresswell \& Stechow 1982). Dalam setiap contoh, para filsuf telah berkontribusi pada pengembangan wilayah penelitian yang terletak tepat di bidang semantik formal.

Selanjutnya pada konteks studi kasus mengenai pragmatik. Dalam sejumlah kasus, para filsuf juga telah hadir pada tahap awal program penelitian pragmatik. Di era millenium para ahli bahasa, misalnya Potts (2005) telah mengembangkan pendekatan yang lebih formal untuk teori tindak tutur yang pertama kali diperkenalkan oleh Grice (1987), dan hal yang sama dapat dikatakan untuk diskusi awal pengandaian di Stalnaker (1970 \& 1974), Lewis (1979) dan Kripke (2009).

Studi kasus yang ketiga ini, tema yang akan penulis diskusikan melibatkan penerapan beberapa literatur yang lebih baru tentang pengandaian dalam memberikan penjelasan tentang pasangan kalimat klasik sebagai berikut ini.

(a) Hesperus adalah Hesperus.

(b) Hesperus adalah Fosfor.

Sejak pengenalan kalimat-kalimat dan pernyataan ini di Frege (1892), para filsuf bahasa telah menghadapi tantangan untuk fakta bahwa kalimat yang berbeda hanya dengan substitusi nama-nama inti dapat menyampaikan informasi yang berbeda.

Beberapa ahli teori referensi langsung berpendapat bahwa perbedaan pragmatis antara (pernyataana) dan (pernyataan-b) bertanggung jawab atas perbedaan informatif (informativeness) mereka sebagaimana yang diungkapkan oleh Salmon (1986), Soames (2002), dan Thau (2002). Pertimbangan terbaru yang diangkat oleh ahli bahasa mengkonfirmasi strategi umum ini tetapi menyarankan wahana pragmatis baru untuk konten yang disampaikan dalam (pernyataan-b), yaitu konten yang diandaikan (presupposed contents).

Sejauh argumen sintaksis asli yang diuraikan dalam pernyataan diatas bersifat dispositif, teori pragmatis umum tentang perbedaan dalam impor kognitif dibatasi oleh pertimbangan sintaksis. Misalnya, mereka harus mengakomodasi bacaan terikat dari askripsi seperti (pernyataan-c) dibawah ini :

\section{(c) Belum ada wanita di ruangan ini yang menyadari bahwa Cicero adalah mata-mata.}

Stalnaker (1988) memperkenalkan gagasan tentang "derived context” yang sesuai dengan klausa yang disematkan dalam askripsi, dan ada variasi formal lainnya dari gagasan ini (Swanson, 2010) untuk pendekatan alternatif dan perbandingan lebih lanjut antar nama dan ekspresi yang memicu pengandaian lainnya. Dalam rangka memberikan perhitungan seperti itu, akan menjadi fakta penting bahwa pengandaian yang diakomodasi secara lokal dapat diikat oleh operator yang lebih tinggi. Misalnya, secara gamblang, (pernyataan-d) mengandaikan bahwa setiap wanita di ruangan itu percaya bahwa dia sendiri sudah bertemu dengan Amir:

(d) Tidak ada wanita di ruangan ini yang percaya bahwa dia akan bertemu Amir lagi.

Untuk teori pragmatis, bacaan serupa dari pengandaian yang diakomodasi secara lokal cenderung untuk menggambarkan penjelasan pertimbangan sintaksis yang diangkat oleh ujaran terikat dari askripsi 
sikap seperti (pernyataan-c). Hanya untuk mengambil satu contoh, pendukung Teori Representasi Wacana dapat mengklaim sebagai keuntungan bahwa kerangka kerja mereka dengan mudah memodelkan perilaku tersebut misalnya, Asher (1986) untuk analisis teori DR-theoretic analysis of puzzles tentang asumsi sikap, seperti yang ada di Kripke (1979). Bagaimanapun, orang dapat melihat bahwa kendala yang disampaikan oleh linguistik mungkin menjadi panduan yang berguna untuk kemajuan lebih lanjut di sini.

Dalam perspektif yang lebih spesifik mengenai pragmatik dalam interpretasi sastra, Tirto Suwondo (2016) dengan mengutip pertanyaan dari John L. Austin, sekaligus sebagai judul bukunya (1962) "How to Do Things with Words", mengilustrasikan pragmatik dalam studi bahasa. Menurutnya, "pragmatik sastra adalah studi tentang tindakan apa yang sesungguhnya dilakukan dalam kaitannya dengan karya sastra". Bertolak dari kata tindakan itu, T.K. Seung menyatakan bahwa "dalam ruang lingkup semiotik, pragmatik adalah studi tentang penggunaan tanda" (1982). Karena karya sastra bermediumkan bahasa, yang dimaksudkan dengan penggunaan tanda ialah tanda-tanda di dalam komunikasi bahasa.

Dalam studi bahasa, pragmatik muncul sebagai usaha mengatasi kebuntuan semantik dalam menginterpretasi makna kalimat. Mengutip Kempson dalam Darma (2014), teori semantik dianggap masih terbatas kemampuannya untuk menjelaskan fenomena kebahasaan. Pragmatik muncul sebagai usaha untuk mengatasi kebutuhan semantik dalam menafsirkan sebuah makna ujaran dalam kalimat. Pada dasarnya antara semantik dan pragmatik nyaris sama karena berhubungan dengan makna. Namun, segala aspek makna yang tidak tercakup di dalam teori semantik ditelaah oleh pragmatik dengan mempertimbangkan konteksnya, yaitu pembicara, pendengar, pesan, latar atau situasi, saluran, dan kode.

Menurut Suwondo (2016), Morris mengembangkan konsepsi pragmatiknya melalui pembagian triadik tanda model semiotik Charles Sanders Peirce. Dari konsep triadik itu, Morris memperkenalkan tiga elemen signifikasi yang disebut tiga hubungan semiosis, yaitu sarana tanda (the sign vehicle), yang dituju (the designatum), dan penafsir (the interpreter). Dari konsepsi ini Morris membedakan tiga dimensi semiosis, yaitu dimensi sintaksis yang merupakan relasi formal tanda dengan tanda lainnya, dimensi semantis yang merupakan relasi tanda dengan objeknya, dan dimensi pragmatik yang merupakan relasi tanda dengan penafsirnya. Oleh karena itu, Morris mendefinisikan semantik sebagai studi tentang signifikasi tanda dan perilaku interpretan tanpa signifikasi, sedangkan pragmatik didefinisikan sebagai studi tentang asal-usul, penggunaan, dan pengaruh (efek, kesan) tanda dalam perilaku penafsir secara keseluruhan.

Secara kerangka berpikir, bila memfokuskan perhatian pada interpretasi tanda dengan cara melibatkan konteks penggunaan tersebut seperti halnya hermeneutika dalam membaca suatu teks, maka ia tidak dapat menghindar dari prasangka yang dipengaruhi oleh kultur masyarakat, tradisi yang hidup dari berbagai gagasan. Hermeneutika memperhatikan tiga hal sebagai komponen pokok dalam upaya penafsiran, yaitu teks, konteks, kemudian melakukan upaya kontekstualisasi (Faiz, 2003). Karenanya, sebuah teks selalu berdiri di antara penjelasan struktural yang bersifat objektif dan pemahaman hermeneutika yang memberi kesan subjektif, yang saling berhadapan. Dikotomi objektivitas dan subjektivitas ini oleh Ricoeur (dalam Sumaryono, 1999) diselesaikan dengan jalan sistem bolak-balik: penafsir melakukan pembebasan teks (dekontekstualisasi) dengan maksud untuk menjaga otonomi teks ketika penafsir melakukan pemahaman terhadap teks (dalam perspektif pragmatik ini merupakan tindakan ilokusioner). Kemudian penafsir melakukan langkah kembali ke konteks (rekontekstualisasi) untuk melihat latar belakang terjadinya teks dan semacamnya (dalam perspektif pragmatik ini merupakan tindakan perlokusioner).

Secara metodologis, Ricoeur menjelaskan langkah pemahaman itu menjadi tiga, yang berlangsung mulai dari penghayatan terhadap simbol-simbol sampai ke tingkat gagasan tentang berpikir dari simbolsimbol, yaitu: (1) langkah simbolik atau pemahaman dari simbol-simbol, (2) pemberian makna oleh simbol serta penggalian yang cermat atas makna, dan (3) langkah filosofis yaitu berpikir dengan menggunakan simbol sebagai titik-tolaknya (Ricoeur, 2003), Sumaryono (1999), dan Faiz (2003).

Ketiga langkah tersebut erat hubungannya dengan langkah pemahaman bahasa, yakni langkah semantik, refleksif, dan eksistensial atau ontologis. Langkah semantik merupakan pemahaman pada tingkat bahasa yang murni. Hal ini merupakan langkah simbolik atau pemahaman dari simbol-simbol yang bertujuan internal, yakni pemahaman yang didasarkan dari simbol-simbol itu sendiri. Dalam perspektif pragmatik langkah ini merupakan tindakan ilokusioner.

Sementara itu, baik langkah pemahaman refleksif maupun langkah pemahaman eksisitensial bertujuan eksternal dan karenanya merupakan tindakan perlokusioner. Langkah pemahaman refleksif setingkat lebih tinggi--mendekati ontologis--sedangkan langkah pemahaman eksisitensial 
atau ontologis adalah pemahaman pada tingkat keberadaan makna itu sendiri. Ricoeur menegaskan bahwa pemahaman itu pada dasarnya cara berada (mode of being) atau cara menjadi. Bagi Ricoeur, sebab pemahaman adalah salah satu aspek proyeksi Dasein (proyeksi manusia seutuhnya) dan keterbukaannya terhadap being. Oleh sebab itu, kita memahami manusia sebagaimana dia menjadi (dalam Sumaryono, 1999).).

\section{Simpulan}

Ada kehati-hatian para semantikis jika dipisahkan dari filsuf bahasa secara cermat terhadap bidang disiplin yang berdekatan namun sangat berbeda, seperti: morfologi, fonologi, dan sintaksis sebagai lawan dari metafisika, epistemologi, dan filsafat pikiran. Kendati para ahli bahasa dan filsuf terkadang sering terlibat dalam program penelitian serupa hingga menemukan pertanyaan berbeda yang menarik dan argumen berbeda yang paling berguna untuk pembangunan teori. Contoh yang diberikan di sini menggambarkan bahwa perspektif yang berbeda dari ahli bahasa merupakan aset yang berharga; Ini adalah alasan mengapa linguistik menawarkan filosofi bahasa begitu banyak alat yang berguna untuk mengembangkan teori. Dalam hal ini, linguistik adalah seperti disiplin ilmu lain yang dibahas dalam bagian artikel ini seringkali terlibat penelitian antara para ahli bahasa dan filsafat dalam usaha bersama.

Pada akhirnya studi kasus yang dikaji di sini menunjukan kesimpulan sederhana bahwa linguistik memainkan berbagai peran berbeda dalam filsafat bahasa. Ahli bahasa telah memberikan kontribusi tantangan empiris pada teori tentang topik klasik dalam filsafat bahasa, dalam beberapa kasus dengan demikian menghidupkan kembali diskursus atau perdebatan yang perlu dituntaskan. Ahli bahasa telah berdialog langsung dengan filsuf sebagai kolaborator dan penentang teori tertentu. Dan ahli bahasa kadangkadang melanjutkan perdebatan filosofis sampai mereka mungkin secara adil mengklaim telah menyesuaikan perdebatan itu sebagai bagian dari peran linguistik yang signifikan. Dalam beberapa kesempatan, ahli bahasa dan filsuf bahasa telah bekerja secara paralel pada masalah-masalah dan diskursus tertentu, serta peran linguistik dalam diskusi filosofis guna merangsang wacana filsafat bahasa secara proporsional.

Thomason \& Pelletier (2002) menunjukkan satu aspek yang sangat unik dari peran linguistik dalam filsafat: "the results of linguistics - and especially the results of the branches of linguistics concerned with semantics-provide direct intuitions of the sort that have always served as the starting points of philosophical positions". Berdasarkan pengamatan ini, dapat dipahami bahwa peran linguistik dalam filsafat bahasa tidak hanya bervariasi tetapi juga dapat dikembangkan dan diperluas lagi cakupannya. Pertanyaan tentang peran apa yang harus diambil linguistik adalah sebagian pertanyaan filosofis tentang peran intuisi dalam penyelidikan filosofis, dan jawaban atas pertanyaan ini sangat bervariasi menurut para filsuf. Peran yang dimainkan oleh intuisi di setiap bidang berkembang dengan sendirinya di abad kedua puluh satu ini semenjak mesin online dan kecerdasan artifisial lainnya menjadi panduan yang lebih halus untuk penelusuran korpus ahli bahasa seiring meluasnya penelitian filsafat eksperimental yang memicu debat metafilosofis. Tetapi meskipun peran linguistik dalam filsafat bahasa terus berubah, orang mungkin mengenalinya sebagai fakta konstan bahwa hubungan antara disiplin ilmu sangat produktif bagi keduanya.

\section{Ucapan Terima Kasih}

Kami ingin mengucapkan terima kasih kepada semua pihak yang telah berkontribusi dalam penelitian dan penulisan artikel ini, khususnya kepada Dr. Samadi, S.Pd., M.Si dan Hasminto Yusuf, Lc., M.AP yang memberikan komentar dan kritik mendalam yang tak ternilai. Artikel ini mendapat banyak manfaat dari umpan balik mereka. Kami juga ingin mengucapkan terima kasih kepada semua peserta reguler kelompok diskusi ilmu lingustik terapan di STFI Sadra Jakarta yang berkenan untuk membaca draf artikel ini. Sebagian dari penelitian ini telah dipresentasikan pada Seminar Sehari; "Tantangan Filsafat Pendidikan Kontemporer" tahun 2020 di STFI Sadra Jakarta.

\section{Daftar Rujukan}

Asher, Nicholas. "Belief in Discourse Representation Theory." Journal of Philosophical Logic 15 (1986): $127-189$.

Austin, J. L. "Ifs and Cans." In Philosophical Papers, J. O. Urmson \& G. J. Warnock, editors. Oxford University Press, Oxford, first edn. 1956

Austin, J. L. How to Do Things with Words. London \& New York: Oxford University Press, 1962. 
Barwise, John \& Robin Cooper. "Generalized Quantifiers and Natural Language." In Portner \& Partee (2002), 75-126.

Barwise, John \& Robin Cooper. Insensitive Semantics: A Defense of Semantic Minimalism and Speech Act Pluralism. Blackwell Publishing Ltd., Malden, MA, 2005.

Chisholm, Roderick M. "The Contrary-to-Fact Conditional." Mind 55 (220), (1946): 289-307.

Cresswell, Maxwell \& Arnim Stechow. "De Re Belief Generalized." Linguistics and Philosophy 5.4 (1982): 85-92.

Darma, Yoce Aliah. Analisis Wacana Kritis dalam Multiperspektif. Bandung: Refika Aditama, 2014.

Davidson, Donald. "The Logical Form of Action Sentences." In The Logic of Decision and Action, Nicholas Rescher, editor, 81-95. University of Pittsburgh Press, Pittsburgh, 1967.

Dillistone, F.W, The Power of Symbol (Daya Kekuatan Simbol). Terjemahan A. Widyamartaya. Yogyakarta: Kanisius, 2002.

Eco, Umberto. A Theory of Semiotics. Bloomington: Indiana University Press, 1976.

Faiz, Fakhruddin. Hermeneutika Qur'ani. Cet.III. Yogyakarta: Penerbit Qalam, 2003.

von Fintel, Kai. "NPI Licensing, Strawson Entailment, and Context Dependency." Journal of Semantics 16 (1999): 97-148.

von Fintel, Kai. "Counterfactuals in a Dynamic Context." In Ken Hale: A Life in Language, Michael Kenstowicz, editor. MIT Press, Cambridge, 2001.

Foley, William A. "Anthropological Linguistics". Massachusetts: Blackwell Publisher Ltd, 2001.

Frege, Gottlob. "On Sinn and Bedeutung." In The Frege Reader, Michael Beaney, editor, 151-171. Blackwell Publishers, Ltd., Oxford. Translated by Max Black, 1892.

Frege, Gottlob. Presuppositions and Pronouns. Elsevier, Amsterdam, 1999.

Gillies, Thony. "Counterfactual Scorekeeping." Linguistics and Philosophy 30 (2007): 329-360.

Gie, The Liang. Suatu Konsepsi ke Arah Pengertian Bidang Filsafat. Yogyakarta: Karya Kencana, 1977

Glanzberg, Michael. "Definite Descriptions and Quantifier Scope: Some Mates Cases Reconsidered." European Journal of Analytic Philosophy 3 (2007): 133-158.

Goodman, Nelson. "The Problem of Counterfactual Conditionals." Journal of Philosophy 44.5 (1947) : 113-128.

Grice, Paul. "Logic and Conversation." In Studies in the Way of Words. Harvard University Press, Cambridge, 1987.

Hamblin, Charles. "Questions in Montague English.” Foundations of Language 10 (1973): 41-53.

Higginbotham, James. "On Linguistics in Philosophy, and Philosophy in Linguistics." Linguistics and Philosophy 25.5-6 (2002): 57.

Johannesen, Richard L. 1996. Etika Komunikasi. Terjemahan Penerbit Remaja Rosdakarya. Cetakan Pertama. Bandung: P.T, Remaja Rosdakarya.

Kaelan, M.S. Filsafat Bahasa: Masalah dan Perkembangannya. Yogyakarta: Paradigma, 1998.

Kamp, Hans. "Formal Properties of 'Now'." Theoria 37 (1971): 227-274.

Kaplan, David. "Demonstratives: An Essay on the Semantics, Logic, Metaphysics, and Epistemology of Demonstratives and Other Indexicals." In Themes from Kaplan, Joseph Almog, John Perry \& Howard Wettstein, editors, 481-563. Oxford University Press, Oxford, 1977.

King, Jeffrey C. Complex Demonstratives: A Quantificational Account. Cambridge: MIT Press, 2001.

Lewis, David K. Counterfactuals. Basil Blackwell Ltd., Malden, MA, 1973.

Ninan, Dilip. Semantics and the Objects of Assertion. Ms., Department of Philosophy, St. Andrews, 2010.

Nunberg, Geoffrey. "Do You Know What It Means to Miss New Orleans?" Linguistics and Philosophy 25.5-6 (2002): 671-680.

Partee, Barbara H. "Binding Implicit Variables in Quantified Contexts." In Partee (2004a), (1989): 259281.

Perry, John. "Thought Without Representation." Supplementary Proceedings of the Aristotelian Society 60 (1986): 137-152.

Perry, John. "Indexicals, Contexts, and Unarticulated Constituents." In Computing Natural Language, A. Aliseda, R. van Gabeek \& D. Westerståhl, editors, 1-11. CSLI Publications, Stanford, 1998.

Portner, Paul \& Barbara H. Partee, editors. Formal Semantics: The Essential Readings. Blackwell Publishers Ltd., Oxford, 2002.

Potts, Christopher. The Logic of Conventional Implicatures. Oxford: Oxford University Press, 2005.

Pryor, Jim. "Reasons and That-Clauses." Philosophical Issues, 17.1 (2007): 217-244 
Seung, T.K. Semiotics and The Thematics in Hermeneutics. New York: Columbia University Press, 1982. Susanto, Astrid. Filsafat Komunikasi. Bandung: Binacipta, 1976.

Sutrisno, Mudji. Kisi-kisi Estetika. Yogyakarta: Kanisius, 1999.

Sumaryono, E. Hermeneutika (Sebuah Metode Filsafat). Yogyakarta: Kanisius, 1999.

Suwondo, Tirto. "Pragmatisme Pascakolonial (Trilogi Gadis Tangsi dalam Sistem Komunikasi Sastra). Yogyakarta : Pustaka Pelajar, 2016

Stalnaker, Robert C. "A Theory of Conditionals." In Ifs: Conditionals, Belief, Decision, Chance, and Time, William L. Harper, Robert Stalnaker \& Glenn Pearce, editors, 41-55. D. Reidel Publishing Company, Dordrecht, 1968.

Stanley, Jason. "Context and Logical Form." Linguistics and Philosophy 23.4 (2000): 391-434.

Stanley, Jason \& Timothy Williamson. "Knowing How." Journal of Philosophy 98.8 (2001): 411-444.

Thau, Michael. Consciousness and Cognition. Oxford: Oxford University Press, 2002.

Thomason, Richmond \& Francis Pelletier. "Twenty-Five Years of Linguistics and Philosophy." Linguistics and Philosophy 25.5-6 (2002): 507-529.

Veltman, Frank. "Defaults in Update Semantics." Journal of Philosophical Logic 25.3 (1996): 221-261.

Wolter, L. "Demonstratives in Philosophy and Linguistics." Philosophy Compass 4.3 (2009): 451-468. 